\title{
The Effects of Sex and Estrogen on Radiographic Progression of Ankylosing Spondylitis in Korean Patients
}

\author{
Hyemin Jeong, M.D., Ph.D. ${ }^{1}$, Eun-Kyung Bae, M.S. ${ }^{2}$, Jiwon Hwang, M.D., Ph.D. ${ }^{3}$, Eun-Jung Park, M.D. ${ }^{4}$, \\ Jaejoon Lee, M.D., Ph.D. ${ }^{5}$, Chan Hong Jeon, M.D., Ph.D. ${ }^{1}$, Eun-Mi Koh, M.D., Ph.D. ${ }^{5}$, Hoon-Suk Cha, M.D., Ph.D. ${ }^{5}$ \\ ${ }^{1}$ Division of Rheumatology, Department of Internal Medicine, Soonchunhyang University Bucheon Hospital, Bucheon, ${ }^{2}$ Samsung Biomedical \\ Research Institute, Seoul, ${ }^{3}$ Department of Internal Medicine, Samsung Changwon Hospital, Changwon, ${ }^{4}$ Department of Internal Medicine, \\ National Medical Center, ${ }^{5}$ Department of Medicine, Samsung Medical Center, Sungkyunkwan University School of Medicine, Seoul, Korea
}

\begin{abstract}
Objective. Ankylosing spondylitis (AS) is a chronic inflammatory disease with obvious male preponderance. Males show more severe radiographic manifestations compared with females. This study aimed to evaluate the effects of sex and estrogen on the radiographic progression of AS. Methods. A total of 101 patients with AS were included in this study. All of the radiographs were scored using the modified Stoke AS Spine Score (mSASSS). Serum levels of $17 \beta$-estradiol (E2), dickkopf-1 (Dkk1), and leptin were detected by enzyme-linked immunosorbent assay. The generalized estimating equations model was used to evaluate factors associated with spinal radiographic progression. Results. The mean age at disease onset was $27.3 \pm 10.7$ years, and 16 patients $(15.8 \%)$ were female. In the multivariable analysis, body mass index ( $\beta$-coefficient $=0.12 ; p=0.047)$ and levels of Dkk1 $(\beta$-coefficient $=-0.11 ; \mathrm{p}<0.001)$, and female $(\beta$-coefficient $=-1.40 ; \mathrm{p}=0.001)$ were associated with radiographic progression. Among male patients with AS, baseline C-reactive protein $(\beta=0.11 ; \mathrm{p}=0.005)$ and $\operatorname{mSASSS}(\beta=0.21 ; \mathrm{p}=0.030)$ were also associated with radiographic progression. E2 and leptin levels were not significantly related to the radiographic progression. Conclusion. Although female patients were associated with less radiographic progression in AS, there was no significant relationship between serum estrogen level and radiographic progression. Results of current study suggests that genetic factors or other environmental factors associated with female may influence radiographic progression in patients with AS. (J Rheum Dis 2021;28:76-84)
\end{abstract}

Key Words. Ankylosing spondylitis, Estrogen, Female

\section{INTRODUCTION}

Ankylosing spondylitis (AS) is a chronic inflammatory disease that causes inflammation in the sacroiliac joints and spine. AS predominantly affects young males. The male-to-female ratio ranges from approximately 2:1 to 5:1 in patients with AS [1-3]. Male patients are also associated with more severe radiographic progression [1]. The pathogenesis of sexual difference in AS is uncertain. Sexual difference in AS could be due to genetics, environmental factors, or hormones. Kobak et al. [4] reported a male case of coexisting AS and Klinefelter's syndrome. In that case, the disease status of AS was milder both clinically and radiologically. Furthermore, radiologic findings of this case are reported to be similar to radiologic images of female AS cases, and X chromosomes observed in 47XXY may have an important role in the expression of AS disease [5]. Baseline radiographic damage, elevated levels of C-reactive protein, and cigarette smoking are associated with radiographic progression [6]. Although male patients with AS are more often smokers than females with AS, the effect of smoking on the radiographic difference between males and females is uncertain. Jimenez-Balderas et al. [7] reported that $17 \beta$-estradiol

Received : November 5, 2020, Revised : December 9, 2020, Accepted : December 14, 2020

Corresponding to : Hoon-Suk Cha (iD http://orcid.org/0000-0001-5391-5376

Division of Rheumatology, Department of Medicine, Samsung Medical Center, Sungkyunkwan University School of Medicine, 81 Irwon-ro, Gangnam-gu, Seoul 06351, Korea. E-mail : hoonsuk.cha@samsung.com

Copyright (c) 2021 by The Korean College of Rheumatology.

This is an Open Access article, which permits unrestricted non-commerical use, distribution, and reproduction in any medium, provided the original work is properly cited. 
levels was lower in premenopausal female patients with active AS than in inactive AS, and the clinical activity of AS was improved after oral estrogen therapy. On the other hand, Giltay et al. [8] reported that serum testosterone level was not elevated in male patients with AS compared with controls. Both serum testosterone level and the ratio of $17 \beta$-estradiol/testosterone were normal in patients with AS [9].

Estrogen receptors are expressed on most immune cells, and estrogen is involved in the immune response [10]. Estrogen may have an immune-modulatory effect on the disease activity of AS. We previously evaluated the estrogen levels in patients with AS, and we found that high estrogen levels were associated with radiographic progression in AS [11]. This study has limitations due to the small sample size. Therefore, the aim of this study was to investigate the effects of sex and estrogen on the spinal radiographic progression in a large number of patients with AS.

\section{MATERIALS AND METHODS}

\section{Study population}

Subjects were selected from a pool of patients who visited the rheumatologic clinic of Samsung Medical Center in Seoul, South Korea from May 2012 to May 2015. All patients were diagnosed with AS by a rheumatologist and fulfilled the 1984 modified New York criteria for AS [12]. The inclusion criteria were defined as follows: over 18 years of age with the presence of baseline and paired follow-up radiographic data at a minimum interval of two years. Patients who were using anti-tumor necrosis factor (TNF) drugs due to the insufficient effect of non-steroidal anti-inflammatory drugs were also included. Patients whose baseline and recent X-rays of both the cervical and lumbar spine were not available were excluded. Patients with advanced AS whose baseline modified Stoke AS Spine Score (mSASSS) score was 72 (maximal score) were also excluded. Pregnant women were excluded. Forty-seven patients from our previous study were included in this study [11]. Fifty-four patients were newly included for a total of 101 patients analyzed in the current study. The study was approved by the Institutional Review Board (IRB) of Samsung Medical Center, and written informed consent was obtained from all subjects in the study (IRB no. 2012-04-107).

\section{Parameters collected}

The baseline clinical characteristics were collected, including patient symptoms and history, body mass index (BMI), C-reactive protein (CRP), erythrocyte sedimentation ratio (ESR), HLA-B27 test using PCR amplification with sequence-specific primers (BioSewoom Inc., Seoul, Korea), and X-rays of the cervical and lumbar spine. The ESR and CRP levels were measured at the first visit of outpatient clinic. The serum estradiol (E2), Dickkopf-1 (Dkk1), and leptin levels were measured in all patients using a human estrogen (E) enzyme-linked immunosorbent assay (ELISA) kit (CUSABIO, College Park, MD, USA), Dkk1 ELISA kit (R\&D Systems, Minneapolis, MN, USA), and leptin ELISA kit (R\&D Systems). Blood samples were obtained once at a routine visit at the rheumatologic clinic during the enrollment period. For females, menstrual cycle information was inquired about in an interview before the blood test, which was performed only in the follicular phase. Additional information regarding the presence or history of uveitis or enthesitis, psoriasis, inflammatory bowel disease, and peripheral arthritis was obtained from medical records.

\section{Radiographic scoring}

Paired recent radiographs of the cervical and lumbar spine and those at baseline were scored in all patients. All of the images collected during the follow-up periods were scored by two trained rheumatologists using the mSASSS [13]. Readers were blinded to the patient's clinical characteristics but knew the chronology. The mean scores of the two readers were calculated. The X-ray follow-up duration was defined as the time interval between the baseline and the collection date of the most recent images. The change in the mSASSS unit between baseline and the most recent image was divided by the X-ray follow-up duration. Patients with an mSASSS progression $\geq 1$ unit/year were defined as progressors, and patients with a rate $<1$ unit/year were defined as non-progressors. The sacroiliitis grade was defined as the sum of the right and left sacroiliitis grades according to the modified New York criteria [12]. The intra-class correlation coefficient of the score for the two readers was 0.88 (95\% confidence interval $0.66 \sim 0.97$ ).

\section{Statistical analysis}

Descriptive statistics were used to identify the characteristics of the study population. Clinical comparisons were performed using t-tests, and the Mann-Whitney 
U-test was performed for continuous variables, as appropriate. Chi-square tests were used for categorical variables. The Spearman correlation analysis was used to investigate the relationship between disease duration and initial mSASSS. Radiographic progression over time was investigated using generalized estimating equations (GEE). The variables associated with $p$-value $\leq 0.20$ were included in the multivariate analysis. A simple correlation analysis was used to analyze the correlation between two continuous parameters. Statistical analysis was executed using SAS version 9.4 (SAS Institute, Cary, NC, USA) and $\mathrm{R}$ version 3.0.3 (The $\mathrm{R}$ Foundation for Statistical Computing, Vienna, Austria).

\section{RESULTS}

A total of 101 patients were included and analyzed. The clinical characteristics of the patients are shown in Table 1. The mean age at disease onset was $27.3 \pm 10.7$ years, and 16 patients (15.8\%) were female. Mean E2 level was $113.2 \pm 37.4 \mathrm{pg} / \mathrm{mL}$. Eighty-six patients (85.2\%) used anti-TNF agents. Female patients showed lower initial mSASSS score than male patients. Leptin level was higher and BMI was lower in female patients than in male patients. The X-ray follow-up duration was significantly higher in male patients than in female patients (97.2 \pm 60.9 vs. $58.5 \pm 54.3$ months; $\mathrm{p}=0.020)$. Among the 101 patients, 35 (34.7\%) were categorized as progressors ( $\triangle \mathrm{mSASSS} /$ year $\geq 1$ unit/year), and $66(65.3 \%)$ were categorized as non-progressors $(\triangle \mathrm{mSASSS} /$ year $<1$ unit/year). Table 2 shows a comparison of the characteristics of non-progressors and progressors. Disease duration before the initial rheumatology department visit was significantly longer in progressors than in non-progressors. The proportion of females was significantly higher in the non-progressor group than the progressor group. E2 level was significantly higher in the progressor group compared with the non-progressor group. Initial CRP level and BMI were significantly higher in the progressor group. The Dkk1 level was significantly lower in the progressor group, and leptin levels were not significantly different between the two groups. Figure 1A shows the natural course of radiographic progression in patients with AS. Variable progression rates were seen within and across patients. The mean X-ray follow-up time was $91.2 \pm 61.2$ months, and the mean $\triangle \mathrm{mSASSS} /$ year was

Table 1. Baseline clinical characteristics

\begin{tabular}{lccc}
\hline \multicolumn{1}{c}{ Variable } & Male $(\mathrm{n}=85)$ & Female $(\mathrm{n}=16)$ & $\mathrm{p}$-value \\
\hline Age at disease onset $(\mathrm{yr})$ & $26.6 \pm 10.8$ & $31.4 \pm 9.7$ & 0.100 \\
Age at estrogen sampling (yr) & $38.3 \pm 11.4$ & $39.3 \pm 8.8$ & 0.739 \\
Disease duration (mo) & $55.6 \pm 66.7$ & $29.3 \pm 29.0$ & 0.126 \\
Peripheral arthritis & $38(44.7)$ & $7(43.8)$ & 0.944 \\
Hip involvement & $19(22.4)$ & $2(12.5)$ & 0.512 \\
Uveitis & $23(27.1)$ & $4(25.0)$ & 1.000 \\
Enthesitis & $12(14.1)$ & $2(12.5)$ & 1.000 \\
mSASSS, initial & $8.9 \pm 11.2$ & $4.0 \pm 3.2$ & 0.001 \\
mSASSS, final & $20.3 \pm 21.9$ & $10.9 \pm 9.3$ & 0.188 \\
Sacroiliitis grade* & $5.5 \pm 1.6$ & $5.1 \pm 1.5$ & 0.337 \\
E2 $(\mathrm{pg} / \mathrm{mL})^{\dagger}$ & $114.1 \pm 35.9$ & $108.8 \pm 45.7$ & 0.552 \\
Dkk1 (ng/mL) & $1,243.5 \pm 760.4$ & $962.0 \pm 521.7$ & 0.160 \\
Leptin (pg/mL) & $1,896.1 \pm 1,847.5$ & $2,968.5 \pm 2,361.3$ & 0.045 \\
ESR, initial (mm/h) & $51.9 \pm 31.9$ & $60.2 \pm 39.7$ & 0.361 \\
CRP, initial (mg/dL) & $3.17 \pm 3.68$ & $1.93 \pm 2.07$ & 0.196 \\
BMI $\left(\mathrm{kg} / \mathrm{m}^{2}\right)$ & $24.6 \pm 3.8$ & $22.2 \pm 2.7$ & 0.018 \\
Anti-TNF use & $74(87.1)$ & $12(75.0)$ & 0.250 \\
Current smoker & $31(36.5)$ & $0(0.0)$ & 0.002 \\
X-ray follow-up duration $(\mathrm{mo})$ & $97.2 \pm 60.9$ & $58.5 \pm 54.3$ & 0.020
\end{tabular}

Data are expressed as mean \pm standard deviation or number (\%). mSASSS: modified Stoke Ankylosing Spondylitis Spine Score, E2: $17 \beta$-estradiol, Dkk1: dickkopf-1, ESR: erythrocyte sedimentation rate, CRP: C-reactive protein, BMI: body mass index, TNF: tumor necrosis factor. *Sacroiliitis grade refers to the sum of sacroiliitis grades of each side according to the modified New York criteria.

${ }^{\dagger}$ Reference range for $\mathrm{E} 2$ are $0 \sim 400 \mathrm{pg} / \mathrm{mL}$. 
Table 2. Comparison of characteristics between non-progressors ( $\triangle \mathrm{mSASSS}<1$ unit/year) and progressors $(\Delta \mathrm{mSASSS} \geq 1$ unit/year)

\begin{tabular}{|c|c|c|c|}
\hline Variable & Non-progressor $(n=66)$ & Progressor $(n=35)$ & p-value \\
\hline Age at disease onset (yr) & $26.8 \pm 11.5$ & $28.3 \pm 9.2$ & 0.528 \\
\hline Age at estrogen sampling (yr) & $36.3 \pm 11.6$ & $42.6 \pm 8.5$ & 0.006 \\
\hline Disease duration (mo) & $37.1 \pm 38.4$ & $78.4 \pm 87.5$ & 0.011 \\
\hline Female & $14(21.2)$ & $2(5.7)$ & 0.048 \\
\hline Peripheral arthritis & $32(48.5)$ & $13(37.1)$ & 0.275 \\
\hline Hip involvement & $17(25.8)$ & $4(11.4)$ & 0.123 \\
\hline Uveitis & $18(27.3)$ & $9(25.7)$ & 0.866 \\
\hline Enthesitis & 9 (13.6) & $5(14.3)$ & 0.928 \\
\hline mSASSS, initial & $3.8 \pm 4.5$ & $16.3 \pm 13.4$ & $<0.001$ \\
\hline mSASSS, final & $17.9 \pm 20.2$ & $21.6 \pm 22.7$ & 0.445 \\
\hline Sacroiliitis grade* & $4.94 \pm 1.37$ & $6.31 \pm 1.62$ & $<0.001$ \\
\hline Estrogen $(\mathrm{pg} / \mathrm{mL})^{\dagger}$ & $107.7 \pm 37.5$ & $123.6 \pm 35.6$ & 0.042 \\
\hline Dkk1 (ng/mL) & $1,303.7 \pm 778.9$ & $1,001.2 \pm 598.7$ & 0.048 \\
\hline Leptin (pg/mL) & $1,939.0 \pm 1,838.8$ & $2,305.4 \pm 2,189.4$ & 0.375 \\
\hline ESR, initial (mm/h) & $49.1 \pm 35.4$ & $61.0 \pm 27.3$ & 0.087 \\
\hline CRP, initial (mg/dL) & $2.31 \pm 2.75$ & $4.21 \pm 4.37$ & 0.024 \\
\hline $\mathrm{BMI}\left(\mathrm{kg} / \mathrm{m}^{2}\right)$ & $23.1 \pm 3.2$ & $26.3 \pm 3.8$ & $<0.001$ \\
\hline Anti-TNF use & $53(80.3)$ & $33(94.3)$ & 0.079 \\
\hline Current smoker & $17(25.8)$ & $14(40.0)$ & 0.140 \\
\hline X-ray follow-up duration (mo) & $93.3 \pm 58.3$ & $119.1 \pm 66.9$ & 0.080 \\
\hline
\end{tabular}

Data are expressed as mean \pm standard deviation or number (\%). mSASSS: modified Stoke Ankylosing Spondylitis Spine Score, Dkk1: dickkopf-1, ESR: erythrocyte sedimentation rate, CRP: C-reactive protein, BMI: body mass index, TNF: tumor necrosis factor, E2: $17 \beta$-estradiol. *Sacroiliitis grade refers to the sum of sacroiliitis grades of the each sides according to the modified New York criteria. ${ }^{\dagger}$ Reference ranges for $\mathrm{E} 2$ are $0 \sim 400 \mathrm{pg} / \mathrm{mL}$.

A



B

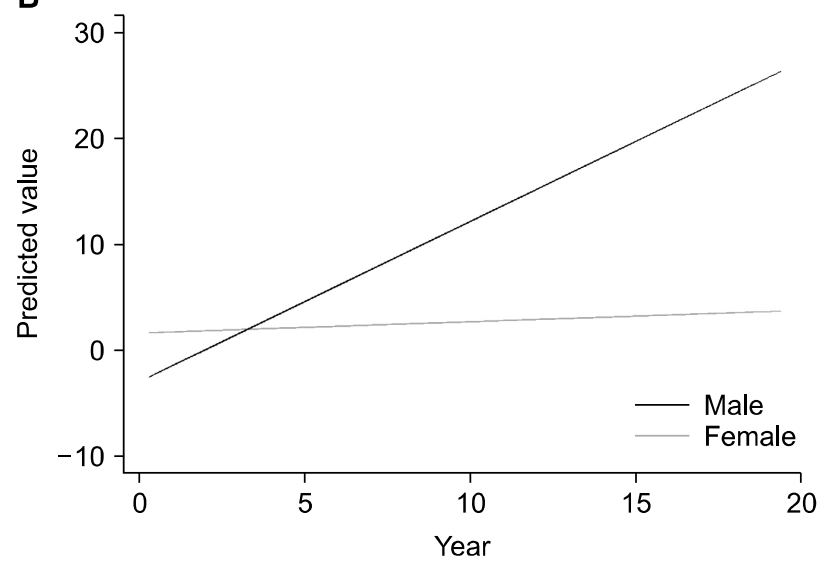

Figure 1. (A) The natural course of radiographic progression. The black line indicates the mean radiographic progression of the entire patient cohort. (B) Predicted value of radiographic progression over time in multivariable analysis according to sex. mSASSS: modified Stoke Ankylosing Spondylitis Spine Score.

$1.03 \pm 1.36$ units/year. The X-ray follow-up duration was not significantly different between non-progressors and progressors (93.3 \pm 58.3 vs. $119.1 \pm 66.9$ months; $\mathrm{p}=0.080$ ). Among the male patients, $33(38.8 \%)$ were categorized as progressors, and $52(61.2 \%)$ were categorized as non- progressors (Table 3). Initial mSASSS, Dkk1, initial CRP and BMI levels were significantly different between non-progressors and progressors among male patients. Interactions with clinical characteristics on spinal radiographs with the GEE model are shown in Table 4. In uni- 
Hyemin Jeong et al.

Table 3. Comparison of characteristics between non-progressors ( $\triangle \mathrm{mSASSS}<1$ unit/year) and progressors $(\Delta \mathrm{mSASSS} \geq 1$ unit/year) among male patients with ankylosing spondylitis $(n=85)$

\begin{tabular}{|c|c|c|c|}
\hline Variable & Non-progressor $(\mathrm{n}=52)$ & Progressor $(n=33)$ & p-value \\
\hline Age at disease onset (yr) & $25.9 \pm 11.8$ & $27.5 \pm 8.9$ & 0.507 \\
\hline Age at estrogen sampling (yr) & $35.6 \pm 12.1$ & $42.6 \pm 8.7$ & 0.005 \\
\hline Disease duration (mo) & $38.5 \pm 40.4$ & $82.4 \pm 88.6$ & 0.003 \\
\hline Peripheral arthritis & $26(50.0)$ & $12(36.4)$ & 0.218 \\
\hline Hip involvement & $15(28.8)$ & $4(12.1)$ & 0.108 \\
\hline Uveitis & $14(26.9)$ & $9(27.3)$ & 0.972 \\
\hline Enthesitis & $7(13.5)$ & $5(15.2)$ & 0.827 \\
\hline mSASSS, initial & $3.9 \pm 4.8$ & $16.8 \pm 13.7$ & $<0.001$ \\
\hline mSASSS, final & $19.2 \pm 21.5$ & $22.0 \pm 23.0$ & 0.601 \\
\hline Sacroiliitis grade* & $4.90 \pm 1.33$ & $6.39 \pm 1.61$ & $<0.001$ \\
\hline Estrogen $(\mathrm{pg} / \mathrm{mL})^{\dagger}$ & $109.6 \pm 36.7$ & $121.1 \pm 34.1$ & 0.153 \\
\hline Dkk1 (ng/mL) & $1,384.0 \pm 823.6$ & $1,022.1 \pm 595.0$ & 0.032 \\
\hline Leptin (pg/mL) & $1,591.7 \pm 1,497.3$ & $2,375.7 \pm 2,235.8$ & 0.082 \\
\hline ESR, initial (mm/h) & $47.2 \pm 34.3$ & $59.3 \pm 26.6$ & 0.088 \\
\hline CRP, initial (mg/dL) & $2.51 \pm 2.96$ & $4.19 \pm 4.44$ & 0.039 \\
\hline $\mathrm{BMI}\left(\mathrm{kg} / \mathrm{m}^{2}\right)$ & $23.4 \pm 3.3$ & $26.5 \pm 3.7$ & $<0.001$ \\
\hline Anti-TNF use & $43(82.7)$ & $31(93.9)$ & 0.132 \\
\hline Current smoker & $17(32.7)$ & $14(42.4)$ & 0.364 \\
\hline X-ray follow-up duration (mo) & $88.7 \pm 58.3$ & $110.6 \pm 63.4$ & 0.106 \\
\hline
\end{tabular}

Data are expressed as mean \pm standard deviation or number (\%). mSASSS: modified Stoke Ankylosing Spondylitis Spine Score, Dkk1: dickkopf-1, ESR: erythrocyte sedimentation rate, CRP: C-reactive protein, BMI: body mass index, TNF: tumor necrosis factor, E2: $17 \beta$-estradiol. *Sacroiliitis grade refers to the sum of sacroiliitis grades of the each sides according to the modified New York criteria. ${ }^{\dagger}$ Reference ranges for $\mathrm{E} 2$ are $0 \sim 400 \mathrm{pg} / \mathrm{mL}$.

Table 4. Interactions with baseline characteristics and spinal radiographic progression with generalized estimating equations model $(n=101)$

\begin{tabular}{|c|c|c|c|c|}
\hline \multirow{2}{*}{ Variable } & \multicolumn{2}{|c|}{ Univariate analysis } & \multicolumn{2}{|c|}{ Multivariable analysis } \\
\hline & $\beta(95 \% \mathrm{Cl})$ & p-value & $\beta(95 \% \mathrm{Cl})$ & $p$-value \\
\hline Time & $1.68(1.04 \sim 2.32)$ & $<0.001$ & $-1.22(-4.71 \sim 2.28)$ & 0.494 \\
\hline Time*female & $-1.44(-2.18 \sim-0.70)$ & $<0.001$ & $-1.40(-2.27 \sim-0.54)$ & 0.001 \\
\hline Time* current smoker & $-0.19(-0.18 \sim 1.10)$ & 0.772 & & \\
\hline Time*uveitis & $-0.22(-1.52 \sim 1.08)$ & 0.738 & & \\
\hline Time*enthesitis & $-1.04(-1.87 \sim-0.22)$ & 0.013 & $0.29(-0.43 \sim 1.01)$ & 0.430 \\
\hline Time* peripheral arthritis & $-1.24(-2.33 \sim-0.16)$ & 0.025 & $-0.37(-1.29 \sim 0.56)$ & 0.438 \\
\hline Time*hip arthritis & $-0.23(-1.65 \sim 1.19)$ & 0.749 & & \\
\hline Time*anti TNF use & $-0.26(-2.42 \sim 1.90)$ & 0.811 & & \\
\hline Time*leptin/100 & $-0.01(-0.02 \sim 0.01)$ & 0.472 & & \\
\hline Time*Dkk1/100 & $-0.11(-0.03 \sim-2.69)$ & 0.007 & $-0.11(-0.13 \sim-0.06)$ & $<0.001$ \\
\hline Time*estrogen & $-0.01(-0.03 \sim 0.01)$ & 0.313 & & \\
\hline Time*age at symptom onset & $0.07(0.03 \sim 0.12)$ & 0.002 & $0.03(-0.01 \sim 0.07)$ & 0.098 \\
\hline Time*initial ESR & $0.01(-0.01 \sim 0.02)$ & 0.421 & & \\
\hline Time*initial CRP & $0.23(0.08 \sim 0.39)$ & 0.003 & $0.11(-0.01 \sim 0.22)$ & 0.059 \\
\hline Time*BMI & $0.20(0.05 \sim 0.36)$ & 0.011 & $0.12(0.01 \sim 0.25)$ & 0.047 \\
\hline Time*initial mSASSS & $0.04(-0.02 \sim 0.09)$ & 0.186 & $0.00(-0.01 \sim 0.02)$ & 0.798 \\
\hline
\end{tabular}

TNF: tumor necrosis factor, Dkk1: dickkopf-1, ESR: erythrocyte sedimentation rate, CRP: C-reactive protein, BMI: body mass index, mSASSS: modified Stoke Ankylosing Spondylitis Spine Score, Cl: confidence interval. 
variable analysis, age at symptom onset, CRP, and BMI were positively associated with radiographic progression. Female, presence of enthesitis, peripheral arthritis, and Dkk1 level were negatively associated with radiographic progression. In multivariable analysis, Dkk1 was significantly associated with less radiographic progression, and BMI was associated with increased risk of radiographic progression. Female patients were associated with less radiographic progression. However, estrogen level and leptin level were not significantly associated with radiographic progression. Figure 1B shows the predicted value of radiographic progression according to sex in multivariable analysis. The slope of the male patients was higher than that of the females over the follow-up time. In the subgroup analysis of male patients with AS $(\mathrm{n}=85)$, CRP level, BMI, and initial mSASSS were significantly associated with radiographic progression in a multivariable analysis (Table 5). Dkk1 level was associated with decreased risk of radiographic progression. In addition, serum estrogen level and BMI showed a weak positive correlation (Pearson correlation coefficient $[r]=0.225 ; p=0.023)$.

\section{DISCUSSION}

We investigated the effects of sex and estrogen on the radiographic progression of spondyloarthritis (SpA).
Although female was associated with less radiographic progression, estrogen level was not significantly associated with radiographic progression in patients with AS. Several studies have investigated the differences between men and women in patients with AS. These studies correspond well with a previous study in which adrenal and gonadal hormones were not altered in patients with AS [14], and women had less radiographic changes compared with men with AS [15].

The sex hormone estrogen is involved in the immune response and affects lymphoid and myeloid cell differentiation, cytokine production, and Th cell polarization. Estrogen decreased the production of Th1 cells and increased the production of Th2 cells [16]. Estrogen increased IL-10 and IL-4 expression, whereas it decreased the expression of TNF $\alpha$ [17]. Estrogen also inhibits Th17 cell differentiation through downregulation of ROR $\gamma \mathrm{T}$ expression [18]. Thus, in a Th1-mediated autoimmune disease such as rheumatoid arthritis (RA), disease activity often decreases during pregnancy , and Th2-mediated diseases such as systemic lupus erythematosus often flare or initially develop in the postpartum period [19]. In contrast to RA, it seems that pregnancy does not improve the symptoms of AS [20]. Ostensen and Ostensen [21] reported that disease activity during pregnancy was unchanged in $33.2 \%$, improved in $30.9 \%$, and worsened in $32.5 \%$ of patients with AS.

Table 5. Interactions with baseline characteristics and spinal radiographic progression with generalized estimating equations model among male patients with ankylosing spondylitis $(n=85)$

\begin{tabular}{|c|c|c|c|c|}
\hline \multirow{2}{*}{ Variable } & \multicolumn{2}{|c|}{ Univariate analysis } & \multicolumn{2}{|c|}{ Multivariable analysis } \\
\hline & $\beta(95 \% \mathrm{Cl})$ & $p$-value & $\beta(95 \% \mathrm{Cl})$ & $\mathrm{p}$-value \\
\hline Time & $1.78(1.10 \sim 2.46)$ & $<0.001$ & $-1.57(-5.03 \sim 1.90)$ & 0.375 \\
\hline Time* current smoker & $-0.414(-1.73 \sim 0.90)$ & 0.539 & & \\
\hline Time* uveitis & $0.04(-1.32 \sim 1.40)$ & 0.954 & & \\
\hline Time*enthesitis & $-1.02(-1.87 \sim-0.17)$ & 0.018 & $0.19(-0.57 \sim 0.95)$ & 0.619 \\
\hline Time* peripheral arthritis & $-1.31(-2.46 \sim-0.17)$ & 0.025 & $-0.34(-1.23 \sim 0.56)$ & 0.459 \\
\hline Time*hip arthritis & $-0.38(-1.83 \sim 1.08)$ & 0.612 & & \\
\hline Time*leptin/100 & $0.00(0.00 \sim 0.01)$ & 0.383 & & \\
\hline Time*Dkk1/100 & $-0.13(-0.20 \sim-0.05)$ & 0.001 & $-0.10(-0.15 \sim-0.04)$ & 0.001 \\
\hline Time*estrogen & $-0.01(-0.03 \sim 0.01)$ & 0.272 & & \\
\hline Time*age at symptom onset & $0.08(0.02 \sim 0.13)$ & 0.004 & $0.03(-0.01 \sim 0.08)$ & 0.109 \\
\hline Time*initial ESR & $0.01(-0.01 \sim 0.03)$ & 0.468 & & \\
\hline Time*initial CRP & $0.22(0.07 \sim 0.38)$ & 0.005 & $0.11(0.00 \sim 0.23)$ & 0.050 \\
\hline Time*BMI & $0.19(0.03 \sim 0.36)$ & 0.021 & $0.13(0.01 \sim 0.26)$ & 0.039 \\
\hline Time*initial mSASSS & $0.03(-0.02 \sim 0.08)$ & 0.189 & $0.21(0.02 \sim 0.40)$ & 0.030 \\
\hline
\end{tabular}

Dkk1: dickkopf-1, ESR: erythrocyte sedimentation rate, CRP: C-reactive protein, BMI: body mass index, mSASSS: modified Stoke Ankylosing Spondylitis Spine Score, Cl: confidence interval. 
However, postpartum flares were observed in $60 \%$ of the patients. Postpartum flares can be explained by an increase in soluble TNF receptor during pregnancy compared to non-pregnant women and a decrease in the TNF receptor during the postpartum period in patients with rheumatic disease [22].

We previously reported that BMI and estrogen level predict radiographic progression in patients with AS [11]. The results of this study were in contrast to the expectation that estrogen would have an anti-inflammatory effect. Because the number of patients included in the previous study was small, the number of patients enrolled in the current study was twice that of previous studies, and the GEE method was used to analyze factors associated with radiographic progression to adjust for time. Serum levels of leptin and Dkk1 were analyzed as well as other traditional risk factors. Although estrogen level was higher in the progressors than non-progressors, we could not find a statistically significant association between estrogen level and radiographic progression in the GEE analysis in the current study. Interestingly, BMI was significantly associated with radiographic progression in both previous and current studies. Moreover, estrogen level was positively related to BMI in both our previous and current studies, which corresponds well with other reports [23].

Sex hormones can influence body weight and body fat and also affect estrogen level [24]. In males, estrogen is derived from the tissue aromatization of testosterone [23]. However, the serum estradiol level does not decrease with age as much as the serum total testosterone level because aromatase activity increases with age, and there is an age-associated increase in fat mass. Adipokines, which are a secreted form of adipocytes in fat tissue, are bioactive substances having an immunomodulatory effect [25]. Serum levels of adipokines, such as leptin, $\operatorname{TNF} \alpha$, IL-6, and IL-1 $\beta$, positively correlate with BMI, and the concentrations of adipokines are increased in patients with metabolic syndrome [26]. In patients with AS, adipokines are related to spinal radiographic progression. Among adipokines, serum levels of resistin and visfatin are elevated in patients with AS, and visfatin was a predictive factor of radiographic progression [27]. High estrogen levels in patients with radiographic progression might result from the secondary elevation of estrogen caused by fat aromatization. Although leptin level was not significantly associated with radiographic progression in the current study, several adipokines might be associated with a high inflammatory burden in obese patients with AS and ultimately result in more rapid radiographic progression. Obesity is related to a poor response to tumor necrosis factor inhibitor (TNFi) in patients with AS [28]. Obesity is also associated with TNFi discontinuation related with anti-drug antibody formation [29]. We previously investigated the effect of estrogen on the disease activity of SpA using a zymosan-induced SKG mice model, and we found that estrogen significantly reduced the disease activity of SpA [30]. Considering that $\mathrm{BMI}$ was also associated with radiographic progression in AS, the anti-inflammatory effect of estrogen might be overcome by the pro-inflammatory cytokines produced by fat tissue.

Estrogen may aggravate SpA considering the direct modulation of osteoblastic activity by estrogen [31]. Estrogen deficiency causes osteoporosis in postmenopausal women. Pro-inflammatory cytokines such as IL-1, IL-6, and TNF $\alpha$ increase bone resorption and are downregulated by estrogen [32]. Other studies reported that estrogen upregulates TGF $\beta$, an inhibitor of bone resorption that acts on osteoclasts to decrease osteoclast activity and increase apoptosis [33]. Estrogen also suppresses the receptor activator of nuclear factor kappa-B ligand-induced osteoclast differentiation. These reports suggest that estrogen inhibits bone resorption and increases bone formation.

The baseline CRP level and initial mSASSS were also significantly associated with radiographic progression especially in male patients, which is consistent with the results of German Spondyloarthritis Inception Cohort (GESPIC) patients [6]. We also evaluated the role of Wnt inhibitors in the disease activity of SpA. Dkk1 is a potent inhibitor of the Wnt signaling pathway and has been reported to be involved in the etiology of AS. Although Dkk1 has been reported to be involved in the etiology of AS, data on the Dkk1 serum level is conflicting. Daoussis et al. [34] reported that Dkk1 level was increased in patients with AS compared with the control group. However, another study showed that Dkk1 level was lower in patients with AS than the control group [35,36]. A recent meta-analysis reported that serum Dkk1 level was higher in AS patients than in the control group [37]. The current study showed that the Dkk1 level was negatively associated with radiographic progression in patients with SpA. This corresponds well with the previous findings of the GESPIC study, which reported that patients with no syndesmophyte formation show significantly higher 
Dkk1 level compared with those with syndesmophyte formation [38]. In accordance with our results, a recent study showed that Dkk1 level was significantly higher in AS patients with no syndesmophytes [39]. Blockade of Dkk1 significantly reduced bone erosions and osteoclast count in the TNF tg mice model [40]. The Dkk1 blockade enhanced collagen type " $\mathrm{X}$ " expression, which results in the formation of hypertrophic chondrocytes and ankyloses of the sacroiliac joint in the TNF tg mice. Dkk1 level was increased in patients with AS who received NSAID or TNFi $[34,36]$. Although Dkk1 might be dysfunctional in AS [34], the results of the current study suggests that Dkk1 might inhibit radiographic progression in patients with SpA.

There are several limitations in this study. First, most of the patients had established AS and had been treated with appropriate medications for a long time. Although we could not analyze the disease activity of AS such as the Ankylosing Spondylitis Disease Activity Score or Bath Ankylosing Spondylitis Disease Activity Index, the disease activity of most of the included patients was low. It is not suitable to evaluate the effect of estrogen on the early phase of AS. We focused on the effect of estrogen on radiographic progression rather than disease activity. Second, estrogen level was assessed just one time at a routine visit at the rheumatologic clinic during the study enrollment period. Furthermore, estrogen level in the human body is affected by various factors such as sex, age, and BMI. Other unknown confounding factors could not fully be adjusted. A hormone analysis of the human body has limitations, and interpretation must be performed with caution. This is a major limitation to evaluating the effect of estrogen on radiographic progression. Third, estrogen levels were not compared with a normal control group. Forth, the possibility of future radiographic progression in the non-progressor group could not be completely excluded due to variation in the timing of follow-up X-ray. Although patients with a follow-up X-ray for a period of 2 years or longer were included, there is a concern about selection bias. However, we investigated the effects of sex and estrogen on the spinal radiographic progression in SpA patients with relatively long-term X-ray follow-up data including other traditional risk factors.

\section{CONCLUSION}

Although female patients were associated with less ra- diographic progression in AS, there was no significant relationship between serum estrogen level and radiographic progression. In addition, high BMI and lower Dkk1 were associated with spinal radiographic progression. Genetic factors or other environmental factors associated with female may influence radiographic progression in patients with AS rather than female sex hormones. Further study is warranted to evaluate the effects of estrogen on the disease activity of AS and reveal the pathophysiology of estrogen in patients with AS.

\section{CONFLICT OF INTEREST}

No potential conflict of interest relevant to this article was reported.

\section{AUTHOR CONTRIBUTIONS}

H.J. conceptualized the study, collected the data, analyzed data, and drafted the manuscript. E.K.B., E.J.P., and J.H. collected data and analyzed data. J.L., C.H.J., and E.M.K. collected the data and reviewed the article. H.S.C. conceptualized the study, collected the data, and critically reviewed the article.

\section{REFERENCES}

1. Lee W, Reveille JD, Davis JC Jr, Learch TJ, Ward MM, Weisman MH. Are there gender differences in severity of ankylosing spondylitis? Results from the PSOAS cohort. Ann Rheum Dis 2007;66:633-8.

2. Will R, Edmunds L, Elswood J, Calin A. Is there sexual inequality in ankylosing spondylitis? A study of 498 women and 1202 men. J Rheumatol 1990;17:1649-52.

3. Jeong H, Yoon JY, Park EJ, Hwang J, Kim H, Ahn JK, et al. Clinical characteristics of nonradiographic axial spondyloarthritis in Korea: a comparison with ankylosing spondylitis. Int J Rheum Dis 2015;18:661-8.

4. Kobak S, Yalçin M, Karadeniz M, Oncel G. Coexistence of ankylosing spondylitis and Klinefelter's syndrome. Case Rep Rheumatol 2013;2013:543953.

5. Armstrong RD, Macfarlane DG, Panayi GS. Ankylosing spondylitis and Klinefelter's syndrome: does the $\mathrm{X}$ chromosome modify disease expression? Br J Rheumatol 1985;24: 277-81.

6. Poddubnyy D, Haibel H, Listing J, Märker-Hermann E, Zeidler $\mathrm{H}$, Braun J, et al. Baseline radiographic damage, elevated acute-phase reactant levels, and cigarette smoking status predict spinal radiographic progression in early axial spondylarthritis. Arthritis Rheum 2012;64:1388-98.

7. Jimenez-Balderas FJ, Tapia-Serrano R, Madero-Cervera JI, Murrieta S, Mintz G. Ovarian function studies in active ankylosing spondylitis in women. Clinical response to estro- 
gen therapy. J Rheumatol 1990;17:497-502.

8. Giltay EJ, Popp-Snijders C, van Schaardenburg D, Dekker-Saeys BJ, Gooren LJ, Dijkmans BA. Serum testosterone levels are not elevated in patients with ankylosing spondylitis. J Rheumatol 1998;25:2389-94.

9. Arniaud D, Mattei JP, Boyer J, Roux H. Sex hormones in spondylarthropathies. A study in 57 patients. Rev Rhum Engl Ed 1998;65:21-6.

10. Cunningham M, Gilkeson G. Estrogen receptors in immunity and autoimmunity. Clin Rev Allergy Immunol 2011; 40:66-73.

11. Jeong H, Bea EK, Lee J, Koh EM, Cha HS. Body mass index and estrogen predict radiographic progression in the spine in ankylosing spondylitis. Joint Bone Spine 2015;82:473-4.

12. van der Linden S, Valkenburg HA, Cats A. Evaluation of diagnostic criteria for ankylosing spondylitis. A proposal for modification of the New York criteria. Arthritis Rheum 1984;27:361-8

13. Creemers MC, Franssen MJ, van't Hof MA, Gribnau FW, van de Putte LB, van Riel PL. Assessment of outcome in ankylosing spondylitis: an extended radiographic scoring system. Ann Rheum Dis 2005;64:127-9.

14. Straub RH, Struhárová S, Schölmerich J, Härle P. No alterations of serum levels of adrenal and gonadal hormones in patients with ankylosing spondylitis. Clin Exp Rheumatol 2002;20(6 Suppl 28):S52-9.

15. Baraliakos X, Listing J, von der Recke A, Braun J. The natural course of radiographic progression in ankylosing spondylitis: differences between genders and appearance of characteristic radiographic features. Curr Rheumatol Rep 2011; 13:383-7.

16. Giltay EJ, van Schaardenburg D, Gooren LJ, Popp-Snijders C, Dijkmans BA. Androgens and ankylosing spondylitis: a role in the pathogenesis? Ann N Y Acad Sci 1999;876: 340-64; discussion 365.

17. Javadian A, Salehi E, Bidad K, Sahraian MA, Izad M. Effect of estrogen on Th1, Th2 and Th17 cytokines production by proteolipid protein and PHA activated peripheral blood mononuclear cells isolated from multiple sclerosis patients. Arch Med Res 2014;45:177-82.

18. Chen RY, Fan YM, Zhang Q, Liu S, Li Q, Ke GL, et al. Estradiol inhibits Th17 cell differentiation through inhibition of ROR $\gamma \mathrm{T}$ transcription by recruiting the ER $\alpha / \mathrm{REA}$ complex to estrogen response elements of the ROR $\gamma \mathrm{T}$ promoter. J Immunol 2015;194:4019-28.

19. Wilder RL. Hormones, pregnancy, and autoimmune diseases. Ann N Y Acad Sci 1998;840:45-50.

20. Ostensen M, Husby G. Ankylosing spondylitis and pregnancy. Rheum Dis Clin North Am 1989;15:241-54.

21. Ostensen M, Ostensen $\mathrm{H}$. Ankylosing spondylitis--the female aspect. J Rheumatol 1998;25:120-4.

22. Østensen M, Förger F, Nelson JL, Schuhmacher A, Hebisch G, Villiger PM. Pregnancy in patients with rheumatic disease: anti-inflammatory cytokines increase in pregnancy and decrease post partum. Ann Rheum Dis 2005;64:839-44.

23. Vermeulen A, Kaufman JM, Goemaere S, van Pottelberg I. Estradiol in elderly men. Aging Male 2002;5:98-102.

24. O'Sullivan AJ, Hoffman DM, Ho KK. Estrogen, lipid oxidation, and body fat. N Engl J Med 1995;333:669-70.

25. Ouchi N, Parker JL, Lugus JJ, Walsh K. Adipokines in in- flammation and metabolic disease. Nat Rev Immunol 2011;11:85-97.

26. Deng Y, Scherer PE. Adipokines as novel biomarkers and regulators of the metabolic syndrome. Ann N Y Acad Sci 2010;1212:E1-19.

27. Syrbe U, Callhoff J, Conrad K, Poddubnyy D, Haibel H, Junker S, et al. Serum adipokine levels in patients with ankylosing spondylitis and their relationship to clinical parameters and radiographic spinal progression. Arthritis Rheumatol 2015;67:678-85.

28. Micheroli R, Hebeisen M, Wildi LM, Exer P, Tamborrini G, Bernhard J, et al. Impact of obesity on the response to tumor necrosis factor inhibitors in axial spondyloarthritis. Arthritis Res Ther 2017;19:164.

29. Hwang J, Kim HM, Jeong H, Lee J, Ahn JK, Koh EM, et al. Higher body mass index and anti-drug antibodies predict the discontinuation of anti-TNF agents in Korean patients with axial spondyloarthritis. Rev Bras Reumatol Engl Ed 2017;57:311-9.

30. Jeong H, Bae EK, Kim H, Eun YH, Kim IY, Kim H, et al. Estrogen attenuates the spondyloarthritis manifestations of the SKG arthritis model. Arthritis Res Ther 2017;19:198.

31. Majeska RJ, Ryaby JT, Einhorn TA. Direct modulation of osteoblastic activity with estrogen. J Bone Joint Surg Am 1994;76:713-21.

32. Pacifici R. Estrogen, cytokines, and pathogenesis of postmenopausal osteoporosis. J Bone Miner Res 1996;11: 1043-51.

33. Manolagas SC. Birth and death of bone cells: basic regulatory mechanisms and implications for the pathogenesis and treatment of osteoporosis. Endocr Rev 2000;21:115-37.

34. Daoussis D, Liossis SN, Solomou EE, Tsanaktsi A, Bounia $\mathrm{K}$, Karampetsou M, et al. Evidence that Dkk-1 is dysfunctional in ankylosing spondylitis. Arthritis Rheum 2010;62: 150-8.

35. Kwon SR, Lim MJ, Suh CH, Park SG, Hong YS, Yoon BY, et al. Dickkopf-1 level is lower in patients with ankylosing spondylitis than in healthy people and is not influenced by anti-tumor necrosis factor therapy. Rheumatol Int 2012;32: 2523-7.

36. Liao HT, Lin YF, Tsai CY, Chou TC. Bone morphogenetic proteins and Dickkopf-1 in ankylosing spondylitis. Scand J Rheumatol 2018;47:56-61.

37. Zhang L, Ouyang H, Xie Z, Liang ZH, Wu XW. Serum DKK-1 level in the development of ankylosing spondylitis and rheumatic arthritis: a meta-analysis. Exp Mol Med 2016;48:e228.

38. Heiland GR, Appel H, Poddubnyy D, Zwerina J, Hueber A, Haibel $\mathrm{H}$, et al. High level of functional dickkopf-1 predicts protection from syndesmophyte formation in patients with ankylosing spondylitis. Ann Rheum Dis 2012;71:572-4.

39. Sakellariou GT, Iliopoulos A, Konsta M, Kenanidis E, Potoupnis M, Tsiridis E, et al. Serum levels of Dkk-1, sclerostin and VEGF in patients with ankylosing spondylitis and their association with smoking, and clinical, inflammatory and radiographic parameters. Joint Bone Spine 2017;84: 309-15.

40. Uderhardt S, Diarra D, Katzenbeisser J, David JP, Zwerina J, Richards W, et al. Blockade of Dickkopf (DKK)-1 induces fusion of sacroiliac joints. Ann Rheum Dis 2010;69:592-7. 